\title{
Multilinguismo e direitos linguísticos: a cooficialização e a patrimonialização como formas de reconhecimento de línguas minorizadas
}

\section{Marina Mello de Menezes Felix de Souza ${ }^{1}$}

Resumo: O processo de desconcentração administrativa que vigora desde a Constituição Brasileira de 1988 tem desencadeado políticas linguísticas de cooficialização e de patrimonialização de línguas minorizadas, gerando ações glotopolíticas em contextos multilíngues, sobretudo em relação às línguas indígenas e às línguas de imigração. Neste artigo, a partir de uma abordagem bibliográfica e documental, analisamos alguns documentos legislativos educacionais municipais, estaduais e federais, a fim de compreender a ação dos diferentes atores glotopolíticos. Nossa análise baseia-se nos conceitos de Políticas Linguísticas, Políticas Públicas e de Direitos Linguísticos. Contextualizando nossa reflexão no processo de redefinição do papel da União e dos entes federativos, percebemos as políticas de cooficialização e de patrimonialização de línguas minoritárias como um indicativo da autonomia regional. No entanto, os resultados mostram ainda a necessidade de um real planejamento democrático que atenda essas línguas minorizadas.

Palavras-chave: Políticas linguísticas. Políticas públicas. Direitos linguísticos. Constituição Brasileira de 1988. Línguas minoritárias.

ma ação glotopolítica se constitui de intervenções que
impactam diretamente a sociedade e os cidadãos que dela fazem parte. Esse tipo de ação, quando ligada à esfera educacional e linguística, é geralmente proposta, ou mesmo imposta, por instâncias governamentais com diferentes fins, tais como apoiar ou desprestigiar línguas minorizadas,

1 Docente da Graduação (Colegiado de Letras) e da Pós- Graduação em Metodologia de Ensino de Línguas e Literaturas Estrangeiras (EMELLE) da Universidade do Estado do Amapá (UEAP) desde 2018. Possui, doutorado na área de Estudos de Linguagem, mestrado em Linguística e graduação (bacharelado e licenciatura) em Letras, Português-Francês, pela Universidade Federal Fluminense (UFF). 
instaurar processos de educação linguística, promover a revitalização das línguas e propor intervenções que favoreçam o plurilinguismo.

Essas mesmas políticas de línguas, quando atingem o setor educacional público, têm suas ações perpetuadas por meio de manifestações do poder governamental (leis, textos oficiais e jurídicos), tornando-se tão poderosas a ponto de serem capazes de conceder direitos cívicos, propiciar a valorização simbólica de formas linguísticas, favorecer o reconhecimento da dimensão da identidade de um povo e alterar representações sociais e linguísticas. Desse modo, refletirmos sobre as ações linguísticas em prol das línguas minoritárias adotadas pelo poder público no Brasil, nos permite entender a sua planificação e compreender a sua significação.

Após 1988, temos, no Brasil, uma nova estrutura organizacional do sistema político-administrativo. O sistema de gestão das políticas sociais brasileiras foi redesenhado de forma que as diferentes políticas públicas ligadas ao setor educacional ficassem sob responsabilidade do estado e do município. Um exemplo desse processo de desconcentração no âmbito da política linguística é o advento do grande número de políticas estaduais e municipais de reconhecimento e de ensino de línguas e culturas encontradas atualmente em nosso país (MORELLO, 2015a).

É importante salientar que, apenas a partir da Constituição de 1988, os temas relacionados com a extensão dos direitos sociais e políticos dos cidadãos e das chamadas minorias passaram a ter lugar na Lei Maior, resguardando os direitos aos costumes, culturas, línguas, organização social e crenças. Esta Carta Magna apresenta ainda a particularidade de ser uma das grandes responsáveis pela desconcentração do poder da União aos estados e municípios, uma vez que permitiu a eles se tornarem autônomos no que tange à grande maioria das decisões sobre políticas públicas, visto que o art. 18 delibera que: "a organização político-administrativa da República Federativa do Brasil compreende a União, os Estados, o Distrito Federal e os Municípios, todos autônomos, nos termos desta Constituição" 
(BRASIL, 1988).

Portanto, neste artigo, objetivamos investigar algumas decisões políticas pós-1988, marcadas por processos de desconcentração política no Brasil. Essa investigação de âmbito documental e bibliográfico configura-se como um recorte um recorte aprofundado da tese doutoral de Souza (2018) e tem por finalidade entender a movimentação de políticas linguísticas públicas no país no que diz respeito a dois grupos de línguas minorizadas: as línguas indígenas e de imigração.

\section{O conceito de Política Linguística como Política Pública}

Em trabalhos anteriores (SOUZA, 2018; 2019; PEREIRA; SOUZA, 2020), propusemos um modelo de intersecção teórica entre os conceitos de Política Linguística e de Política Pública. Desde a sua criação, a área de política pública (PP) tem dado primazia à produção e à ação do governo, bem como à explicação da natureza da política analisada e a seus processos. Logo, o foco desses estudos estaria em análises da compreensão das consequências que emergem das decisões governamentais. Dessa forma, pesquisadores da área de PP, como Laswell (1936), Lowi (1964), Dye (1984) e Peters (1986), desenvolvem definições de PP com base em uma perspectiva centrista.

Essa visão é problematizada pelo sociólogo inglês Stephen Ball que, com a ajuda de colaboradores (BOWE; BALL; GOLD, 1992; BALL, 1994), elabora a noção de Policy Cycle ou Ciclo Político. Em sua proposta, esse autor se alinha às concepções de Michel Foucault (1997), segundo as quais o poder não estaria localizado em uma única instituição, mas disseminado, podendo ser encontrado até mesmo nas microrrelações sociais que permeiam a sociedade.

A proposta do Ciclo de Políticas caracteriza o processo político como um ciclo contínuo e deliberativo, constituído por um processo 
dinâmico e de constante aprendizado. Esse ciclo é composto pelos estágios de definição de agenda, identificação de alternativas, avaliação das opções, seleção das opções, implementação e avaliação. Destarte, esta abordagem de ciclos entende que toda política pública possui uma sequência de passos, incluindo também a avaliação, mesmo que, na prática, os atores políticoadministrativos dificilmente a sigam. Nesse sentido, acreditamos que a teoria do Ciclo de Políticas se adequa à apreciação de políticas linguísticas e à avaliação de seu impacto na sociedade.

Quanto à PL, esta corresponde, de acordo com Calvet (2002b) ao "conjunto de escolhas conscientes efetuadas no domínio das relações entre língua e vida social, e mais particularmente entre língua e vida nacional", intervindo na situação das línguas. Sua aplicação ou a prática da política estabelecida, chamada de planificação linguística, intervém em conflitos oriundos de diferentes línguas ou como um modo de assinalar relações de poder por meio das línguas.

Rousseau (2015) subdivide as intervenções linguísticas em duas esferas, dialogando com a proposta de políticas in vivo e in vitro de Calvet (2002b). Para Rousseau (2015), as políticas linguísticas podem ser de caráter incitativo e de caráter impositivo. A primeira se refere aos casos em que a autorregulação se apoia em práticas naturais, derivadas dos comportamentos dos locutores, livre de sanções; enquanto a segunda diz respeito aos casos regulamentados por meio de medidas legislativas, eventualmente acompanhadas de sanções.

Um autor que nos apresenta uma tipologia interessante das PL mais frequentemente observadas no mundo é Leclerc (2012). Para ele, existiriam as políticas de assimilação; as políticas de não intervenção; as políticas de valorização da língua oficial; as políticas setoriais; as políticas do status jurídico diferenciado; as políticas de bilinguismo ou de trilinguismo; as políticas de multilinguismo estratégico; as políticas de internacionalização linguística e as políticas linguísticas mistas. 
Segundo o autor, as políticas de assimilação são aquelas que se utilizam de meios extremos a fim de exterminar grupos linguísticos. Essas intervenções englobam ações linguísticas, tais como a proibição, a exclusão, a desvalorização social, a repressão e o genocídio. Em relação às políticas de não intervenção, essas se referem aos casos nos quais os atores políticos resolvem não intervir. As políticas de valorização da língua oficial se constituem - se de ações que promovem o monolinguismo ou a língua oficializada em território nacional. As políticas setoriais são intervenções legislativas ligadas ao uso das línguas minoritárias ou de imigrantes. Um dos campos mais visados por essa política é o domínio educacional, além de aspectos ligados à marcação linguística de território. As políticas do status jurídico diferenciado são intervenções que têm por finalidade a valorização de línguas minoritárias e a harmonização da coabitação linguística, sem atribuir igualdade jurídica a todos. As políticas de bilinguismo ou de trilinguismo são ações linguísticas que se fundamentam em políticas oficializadas por constituições ou leis, tratando-se, geralmente, de uma igualdade jurídica, o que não corresponde, necessariamente, a uma igualdade real, baseada em fatos. Nessas políticas, a escolha da língua utilizada constitui geralmente um direito do indivíduo e uma obrigação por parte do Estado. As políticas de multilinguismo estratégico possuem um caráter essencialmente pragmático. Nelas, apesar de o estado ser oficialmente monolíngue, pode-se recorrer a duas ou mais línguas por necessidades ligadas à comunicação ou à situação política, social e econômica. As políticas de internacionalização linguística dizem respeito às ações de uma ex-potência colonial, com língua de grande difusão e prestígio, tentando estender sua supremacia linguística para além das suas fronteiras. Finalmente, Leclerc (2012) define as Políticas Linguísticas Mistas como sendo a prática simultânea de diferentes tipos de intervenção por parte do Estado.

Atualmente, evidenciam-se no Brasil quatro das tipologias expostas por Leclerc (2012): as políticas setoriais, a do status jurídico diferenciado, a 
de bilinguismo ou de trilinguismo e as linguísticas mistas.

Ao conjecturarmos as situações das línguas oficiais, sendo essas a língua portuguesa e algumas línguas indígenas e de imigrantes. Apesar de o artigo 13 da Constituição Federal Brasileira prever o português como idioma oficial da República Federativa, mais recentemente, a LIBRAS (Língua Brasileira de Sinais) teve o seu ensino previsto em sistemas educacionais por meio do decreto $\mathrm{n}^{\circ} 5.626$, de 22 de dezembro de 2005, e passou a ser oficializada como a língua usada pelos surdos no Brasil. Ainda, as línguas indígenas e de imigrantes (por exemplo: o nheengatu, o otukano, o baniwa, o pomerano, o pomerode, o hunsrückisch, o guarani, etc.) também foram oficializadas no Brasil por meio de leis municipais.

Podemos notar que as tipologias de PP e de PL destacam o papel do Estado em suas implementações sem negligenciar, todavia, o papel das organizações civis. No Brasil, as organizações populares, que se consolidaram nos anos 1980, participaram diretamente do processo de democratização que culminou com a Constituição de 1988. Oliveira (2005), um dos fundadores do Instituto de Investigação e Desenvolvimento em Política Linguística (IPOL), faz uma crítica contundente ao papel do Estado Nacional no processo de planificação linguística. O autor ressalta que, por prezar a homogeneização, o Estado veria a pluralidade linguística como antagônica a seus interesses:

[...] o Estado Nacional é um mau administrador da pluralidade linguística e cultural, simplesmente porque é, por definição, o constructo histórico da homogeneização e da unidade. Os Estados-Nação foram os maiores algozes das línguas; foi por causa, sobretudo dos Estados-Nação que uma imensa quantidade de comunidades linguísticas foram obrigadas a abandonar suas línguas nos últimos 300 anos, quando esta forma de organização societária passou a prevalecer no mundo. A pluralidade linguística, portanto, e re- 
sumindo muito a argumentação, só pode ser administrada em instâncias aquém ou além do Estado-Nação. (OLIVEIRA, 2005)

Os Ciclos de Políticas destacam o processo de descentralização do setor público como um dos fatores contextuais para a implementação de políticas. Ressaltamos, mais uma vez, que, no regime democrático, a descentralização de poder permite a ampla participação de diferentes instâncias da sociedade, e as decisões e os recursos são delegados aos níveis mais baixos de governo (descentralização territorial) ou às autoridades reconstituídas não tradicionais (descentralização funcional). Esse movimento pode ser percebido a partir da Constituição de 1988 e das primeiras políticas linguísticas implementadas na década que se seguiu. Assim, fica evidente a articulação entre os conceitos de PP e de PL, posto que esta última leva em consideração ações oriundas de práticas sociais capazes de motivar intervenções linguísticas oficiais e, como consequência, planificações linguísticas formais, funcionais e de aquisição.

Com o objetivo de abranger a interseção teórica proposta e dar conta das diferentes formas que uma política de línguas é capaz de adquirir no Brasil, propomos a nomenclatura Política Linguística Pública (PLP). Esse conceito se refere às ações geridas pelo poder governamental e elaboradas com a participação de diferentes atores sociais. Dentre elas, distinguimos as Políticas Linguísticas Públicas de Regulação (PLPR), as Políticas Linguísticas Públicas Educacionais ou Educativas (PLPE) e as Políticas Linguísticas Públicas de Nomeação (PLPN).

As PLPR são as intervenções que regulamentam problemas de comunicação por meio de ações facilitadoras ao desenvolvimento do plurilinguismo, como observado em regiões de fronteiras. A título de exemplo de uma PLPR, citamos a lei estadual $n^{\circ} 1406$, de 18 de novembro 
de 2009, do estado do Amapá.2 Essa lei estabelece a inclusão da língua francesa no sistema de ensino do estado.

As PLPE são as intervenções que têm impacto direto nas instituições de ensino, podendo estar incluídas em diversas PLPN e PLPR. Pode ser observada mediante a lei 13.415 , de 16 de fevereiro de 2017, que altera o texto inicial da LDB, de 1996, e inclui a obrigatoriedade do ensino da língua inglesa no ensino fundamental a partir do $6^{\circ}$ ano e no ensino médio.

As PLPN, foco deste artigo, são as intervenções que nomeiam as línguas por intermédio de sua cooficialização em âmbito municipal ou sua patrimonialização em âmbito estadual. A fim de exemplificá-las, citamos a lei $\mathrm{n}^{\circ}$ 14.951, de 11 de novembro de 2009, do estado de Santa Catarina. Essa lei declarou o talian3 um de seus patrimônios históricos e culturais. Logo, sua oficialização objetivou apoiar a língua minoritária de um grupo de falantes que buscavam, no suporte de um texto governamental, sua valorização e o reconhecimento de sua identidade. Posteriormente, essa lei foi revogada pela Lei $n^{\circ}$ lei 17.565 , de 6 de agosto de 2018, que trata, exclusivamente, do Patrimônio Cultural do Estado de Santa Catarina.

\section{O processo de desconcentração das Políticas Linguísticas Públicas}

A Constituição Federal de 1988 conferiu autonomia aos municípios e aos estados, além de criar novos padrões de interação entre o governo e a sociedade, num esforço de assegurar a participação da população que, de acordo com o art. 204, inc. II, da Constituição Federal de 1988, darse-ia por meio de um sistema de organizações representativas ligadas à formulação, à gestão e à implementação de políticas públicas (ROCHA, 2009, p. 7), ou seja, é explícita a mudança político-social e político-

\footnotetext{
2 http://www.al.ap.gov.br/ver_texto_lei.php?iddocumento=26436

3 Língua neolatina originária dos italianos e descendentes radicados de Santa Catarina.
} 
administrativa brasileira durante o processo de redemocratização do país, o que gerou uma desconcentração cada vez mais acentuada da gestão e das políticas públicas, tornando possível, em tese, à comunidade local ter uma maior participação em decisões que lhe coubessem, incluídas aqui muitas das decisões linguísticas.

Assim, a Carta Magna em vigor possui a particularidade de discorrer sobre línguas e comunidades minoritárias, sendo a primeira a citar direitos linguísticos em favor da diversidade e a engendrar a completa autonomia dos entes federados que compõem o país. Esses fatores foram o motor para intervenções linguísticas locais que levassem em conta especificidades regionais, como as Políticas Linguísticas Públicas de Nomeação (PLPN) de línguas indígenas e de imigrantes e as Políticas Linguísticas Públicas Educativas (PLPE) de manutenção linguística. ${ }^{4}$

Tendo em mente que as políticas linguísticas públicas são as grandes responsáveis pela gestão do plurilinguismo nacional, ampliando ou restringindo direitos linguísticos, analisaremos aspectos ligados às Políticas Linguísticas Públicas de Nomeação (PLPN) encontrados atualmente no Brasil.

\section{As Políticas Linguísticas Públicas de Nomeação (PLPN) de línguas de} minoritárias no Brasil: consequências do processo de desconcentração

As Políticas Linguísticas Públicas de Nomeação (PLPN) são políticas que nomeiam uma determinada língua, cooficializando-a por meio de leis e decretos municipais ou patrimonializando-a mediante leis e decretos estaduais. Nesse sentido, Morello (2016) destaca a importância das políticas linguísticas de conhecimento, reconhecimento e promoção

\footnotetext{
4 As PLPN foram promovidas por estados e municípios com a assessoria do recém criado IPOL, fundado em 1999, com sede no município de Florianópolis, no estado de Santa Catarina.
} 
das línguas brasileiras, por intermédio da cooficialização de línguas, executada por decretos e leis municipais, e do Inventário Nacional da Diversidade Linguística (INDL), conduzido pelo governo federal. Baseada no relatório do Grupo de Trabalho da Diversidade Linguística (GTDL), grupo interministerial e interinstitucional, a autora afirma que o reconhecimento e a nomeação das línguas inventariadas como referências culturais brasileiras têm efeitos positivos para a formulação e implantação de políticas públicas, para a valorização da diversidade linguística, para o aprendizado dessas línguas pelas novas gerações e para o desenvolvimento do seu uso em novos contextos.

Essas ações vão ao encontro das concepções de direito e pluralismo linguístico que figuram em declarações e relatórios emitidos pela UNESCO, como na Declaração Universal de Direitos Linguísticos (DUDL, 1996); na Declaração Universal sobre a Diversidade Cultural (DUDC, 2002); e no Relatório Mundial da UNESCO (UNESCO, 2009). Nesses documentos, vemos que essas noções se relacionam diretamente com os verbos preservar, desenvolver e promover no que se refere ao sistema linguístico das comunidades linguísticas.

Considerando que a nomeação da língua é um importante elemento simbólico-político, Boyer (2009, p.16-17) acredita que esse gênero de intervenção, realizado por meio da nomeação, está frequentemente ligado a um posicionamento regionalista ou nacionalista que, por se originar de uma minoria dominada, é geralmente excluído, inteira ou parcialmente, da comunicação pública institucional, incluindo as escolas e o campo educacional como um todo, um dos domínios onde as leis oficiais adquirem grande importância. $\mathrm{O}$ autor destaca que a reivindicação do nome da língua é uma forma de reclamar a sua inscrição em uma comunidade linguística e/ ou cultural e faz parte das lutas por uma denominação legítima.

Sériot (2010) também concorda que o nome é um objeto simbólico com o poder de transformar grupos em objetos contáveis. Dessa forma, a 
importância de nomear uma língua nacional consiste em um ato político que tem relação não apenas com a adequação da palavra, como nome, mas da sua aceitação para designar grupos, isto é, dar nome a uma língua é uma forma de reconhecer uma identidade linguística e cultural.

Em seu estudo sobre as línguas regionais da França, Blanchet (2002, p.87-96) destaca três tomadas de posição por parte do estado: (a) ausência de política; (b) considerá-las ou tratá-las por meio de uma política limitada ao campo cultural; (c) enquadrá-las em uma verdadeira política explícita na esfera governamental.

A primeira posição pode denotar uma falta de engajamento político, constituindo-se em uma forma implícita de política, pretensamente neutra, por não se fazer nada para apoiar a questão das línguas e culturas regionais por falta de engajamento político, o que pode mascarar o desinteresse dos políticos e ajudar na supremacia definitiva das línguas dominantes. Durante muito tempo, o Brasil se comportou dessa maneira, disseminando que a língua portuguesa era a única língua que predominava no país, não reconhecendo e não tecendo políticas globais para as línguas presentes em seu território. Esse fato fez com que muitas desaparecessem e seus locutores fossem marginalizados pela sociedade. Já o ato de considerá-las ou tratálas por intermédio de uma política limitada ao campo cultural é um aspecto que as excluiria da vida social, marginalizando-as e conservando-as sob um aspecto patrimonial, museológico, e não através de uma valorização dinâmica, priorizando seu uso potencial.

Quanto ao terceiro aspecto apontado por Blanchet (2002), aquele da verdadeira política global, seria a forma mais explícita da política. Esses três processos apontados pelo autor nos remetem à complexidade da implementação das PLPN no Brasil, onde políticas para o reconhecimento de línguas como patrimônio bem como as políticas de cooficialização fazem parte de políticas explícitas, oriundas de movimentos entre o Estado e os representantes da sociedade. 
A complexidade à qual aludimos diz respeito à sinergia necessária entre as PLPN e outras decisões político-educativas. Convém ressaltar que a administração do Estado brasileiro é dividida em três níveis de governo: federal, estadual e municipal. Todos os estados, o Distrito Federal e os municípios são membros da Federação - estes últimos a partir da Carta Magna de 1988 - e, assim, têm suas administrações com diferentes níveis de autonomia.

A Constituição define os limites dessa autonomia, determina os assuntos que podem ser legislados, demarca o espaço de ação do poder Executivo e estabelece que não existe hierarquia entre os três níveis. Assim, o processo de desconcentração promovido pela Constituição pós-1988 permitiu a criação de 5.570 municípios, todos com legislações próprias, quer dizer, dotados do poder de autoadministração, autogoverno e auto-organização, divididos em 26 estados federados. Desses, três estados patrimonializaram línguas de imigração e apenas uma língua indígena. No que se refere aos municípios, 34 deles, pertencentes a sete estados brasileiros, possuem políticas linguísticas de cooficialização.

Abaixo, apresentamos um quadro que contempla os dados relativos às línguas indígenas:

Quadro 1 - Políticas Linguísticas Públicas de Nomeação de línguas indígenas

\begin{tabular}{|c|c|c|c|}
\hline \multirow{2}{*}{ Estado } & $\begin{array}{c}\text { Língua } \\
\text { Patrimonializada } \\
\text { (estado) }\end{array}$ & Município & $\begin{array}{c}\text { Língua } \\
\text { Cooficializada } \\
\text { (município) }\end{array}$ \\
\hline \multirow{2}{*}{ Amazonas } & $\begin{array}{c}\text { Não há patrimonialização } \\
\text { de línguas }\end{array}$ & $\begin{array}{c}\text { São Gabriel da Cachoeira (lei } \\
\mathrm{n}^{\circ} 145 / 2002 \text { lei no } 210 / 2016- \\
\text { regularização }\end{array}$ & $\begin{array}{c}\text { Nheengatu, baniwa, } \\
\text { tukano. }\end{array}$ \\
\cline { 3 - 4 } & & $\begin{array}{c}\text { Santo Antônio do Iça (número } \\
\text { de lei não identificada/2020) }\end{array}$ & Ticuna \\
\hline
\end{tabular}




\begin{tabular}{|c|c|c|c|}
\hline $\begin{array}{l}\text { Mato } \\
\text { Grosso do } \\
\text { Sul }\end{array}$ & $\begin{array}{c}\text { Não há patrimonialização } \\
\text { de línguas }\end{array}$ & $\begin{array}{c}\text { Tacuru (lei no } 848 ; \\
\text { Projeto de lei 009/2010) }\end{array}$ & Guarani \\
\hline Tocantins & $\begin{array}{c}\text { Não há patrimonialização } \\
\text { de línguas }\end{array}$ & $\begin{array}{l}\text { Tocantínia (número de lei não } \\
\text { identificada/agosto de 2012) }\end{array}$ & Akwê xerente \\
\hline \multirow{2}{*}{ Roraima } & \multirow{2}{*}{$\begin{array}{c}\text { Não há patrimonialização } \\
\text { de línguas }\end{array}$} & Bonfim (lei no 211/2014) & \multirow{2}{*}{$\begin{array}{c}\text { Macuxi, wapichana e } \\
\text { Ticuna }\end{array}$} \\
\hline & & Cantá (lei n² 281/2014) & \\
\hline $\begin{array}{l}\text { Rio de } \\
\text { Janeiro }\end{array}$ & $\begin{array}{c}\text { Iorubá (lei } \mathrm{n}^{\circ} 8085 / 2018 \\
\text { - Projeto de lei } \mathrm{n}^{\circ} \\
3416 / 2017)^{56}\end{array}$ & - & $\begin{array}{c}\text { Não há } \\
\text { cooficialização de } \\
\text { línguas }\end{array}$ \\
\hline
\end{tabular}

Fonte: elaboração própria.

Conforme podemos observar no quadro, apenas um estado patrimonializou línguas indígenas, e seis municípios, presentes em quatro outros estados, as cooficializaram. No entanto, os números de cooficializações tendem a aumentar se considerarmos as informações disponibilizadas pelo IPOL (2021). Elas apontam que três Projetos de Lei foram aprovados e aguardam o parecer do Executivo. São eles os projetos de lei que cooficializam as línguas Ingaricó, no município de Uiramutã, em Roraima; Saterê Mauê, no município de Mauês, no Amazonas; e Mebêngôkre (Kayapó), no município de São Félix do Xingu, no Pará. Acrescentamos a esses dados o Projeto de lei $n^{0}$ 045/20207, que disserta sobre a cooficialização da língua tenetehara-guajajara no município de Barra do Corda, no estado do Maranhão.

O censo realizado pelo IBGE em 2010 aponta que o Brasil possui 896.917 pessoas que se autodeclararam indígenas, ou seja, cerca de $0,47 \%$

\footnotetext{
5 https://leisestaduais.com.br/rj/lei-ordinaria-n-8085-2018-rio-de-janeiro-declara-patrimonio-imaterial-doestado-do-rio-de-janeiro-o-idioma-em-ioruba-praticado-nas-religioes-afro-brasileiras

6 http://alerjln1.alerj.rj.gov.br/scpro1519. nsf/1061f759d97a6b24832566ec0018d832/53a08f88f0973c61832581a200608770?OpenDocument

7 http://ojs.fsg.br/index.php/congressodedireitoshumanos/article/view/4506
} 
da população total do país. Dessas, $28,8 \%$ não falam o português e sim uma das 274 línguas indígenas registradas. Aproximadamente, 324.834 indígenas vivem em cidades, enquanto 572.083 habitam zonas rurais (FUNAI, 2017; CDI, 2017). Segundo o Programa Povos Indígenas no Brasil, grande parte dessa população se encontra em aldeias localizadas em 713 terras indígenas presentes em todo o território nacional (PIB, [201]). Cada um desses povos indígenas possui uma identidade linguística própria que, em sua maioria, de acordo com o atlas interativo da UNESCO (MOSELEY, 2010), corre perigo de extinção. Assim, percebemos que as PLPN, enquanto cooficialização, são de grande relevância para a sua proteção e valorização.

A seguir, apresentamos um segundo quadro relativo aos dados ligados às línguas de imigrantes:

Quadro 2 - Políticas Linguística Públicas de Nomeação de línguas de imigrantes

\begin{tabular}{|c|c|c|c|}
\hline Estado & $\begin{array}{c}\text { Língua } \\
\text { Patrimonializada } \\
\text { (estado) }\end{array}$ & Município & $\begin{array}{c}\text { Língua } \\
\text { Cooficializada } \\
\text { (município) }\end{array}$ \\
\hline \multirow{7}{*}{$\begin{array}{l}\text { Espírito } \\
\text { Santo }\end{array}$} & \multirow{7}{*}{$\begin{array}{c}\text { Pomerano e alemão } \\
\text { (Proposta de Emenda } \\
\text { Constitucional (PEC) } \\
\mathrm{n}^{\circ} 11 / 2009 \text { - Emenda } \\
\text { Constitucional no } \\
64 / 11)^{8}\end{array}$} & Pancas (lei n 987/2007) & \multirow{7}{*}{ Pomerano } \\
\hline & & Laranja da Terra (lei no 510/2008) & \\
\hline & & $\begin{array}{l}\text { Santa Maria de Jetibá (lei n 1136/ } \\
\text { 2009) }\end{array}$ & \\
\hline & & Vila Pavão (lei no 671/2009) & \\
\hline & & $\begin{array}{l}\text { Domingos Martins (lei } \mathrm{n}^{\circ} \\
59 / 2011)\end{array}$ & \\
\hline & & Itarana (lei no $1195 / 2016)$ & \\
\hline & & Canguçu (lei no $3473 / 2010)$ & \\
\hline
\end{tabular}




\begin{tabular}{|c|c|c|c|}
\hline \multirow{16}{*}{$\begin{array}{l}\text { Rio Grande } \\
\text { do Sul }\end{array}$} & \multirow{16}{*}{$\begin{array}{c}\text { Não há } \\
\text { patrimonialização da } \\
\text { língua pomerana, mas } \\
\text { das línguas Talian (lei } \\
\mathrm{n}^{\circ} 13.178 / 2009^{9} \text { ) e } \\
\text { Hunsrückisch (lei no }^{\circ} \\
14.061 / 2012)^{10}\end{array}$} & $\begin{array}{c}\text { São Lourenço do Sul (número de } \\
\text { lei não identificada) }\end{array}$ & \multirow{14}{*}{ Talian } \\
\hline & & Serafina Corrêa (lei no 2615/2009) & \\
\hline & & $\begin{array}{c}\text { Flores da Cunha (lei } n^{\circ} \\
3.180 / 2015)\end{array}$ & \\
\hline & & $\begin{array}{c}\text { Nova Roma do Sul (lei } \mathrm{n}^{\circ} \\
1.310 / 2015)\end{array}$ & \\
\hline & & Nova Erechim (lei $\left.\mathrm{n}^{\circ} 1.783 / 2015\right)$ & \\
\hline & & Paraí (lei no 3122/2015) & \\
\hline & & $\begin{array}{c}\text { Bento Gonçalves (lei } \mathrm{n}^{\circ} \\
6.109 / 2016)\end{array}$ & \\
\hline & & $\begin{array}{c}\text { Fagundes Varela (lei }{ }^{\circ} \\
1.922 / 2016\end{array}$ & \\
\hline & & Antônio Prado (lei n 3.017/2016) & \\
\hline & & Guabiju (lei n $1.315 / 2016)$ & \\
\hline & & Caxias do Sul (lei n 8.208/2017) & \\
\hline & & $\begin{array}{c}\text { Camargo (lei Ordinária } \mathrm{n}^{\circ} \\
1.798 / 2017 \text { ) }\end{array}$ & \\
\hline & & Ivorá (lei nº 1.307/2018) & \\
\hline & & $\begin{array}{c}\text { Nova Pádua (lei Municipal nº } \\
1.214 / 2020)\end{array}$ & \\
\hline & & Westfália (lei nº 1302/2016) & Plattdeutsch \\
\hline & & $\begin{array}{l}\text { Santa Maria do Herval (número } \\
\text { de lei não identificado/2010) }\end{array}$ & Hunsrückisch \\
\hline
\end{tabular}

9 https://www.estado.rs.gov.br/governadora-sanciona-lei-que-declara-o-talian-dialeto-integrante-dopatrimonio-do-rs

10 https://www.estado.rs.gov.br/governadora-sanciona-lei-que-declara-o-talian-dialeto-integrante-dopatrimonio-do-rs 


\begin{tabular}{|c|c|c|c|}
\hline \multirow{4}{*}{$\begin{array}{c}\text { Santa } \\
\text { Catarina }\end{array}$} & \multirow{4}{*}{$\begin{array}{c}\text { Talian (lei } \mathrm{n}^{\circ} \\
14.951 / 2009- \\
\text { revogada pela lei } \mathrm{n}^{\circ} \\
17.565 / 2018)\end{array}$} & Antônio Carlos (lei n 132/2010) & \\
\hline & & Ipumirim (lei no $1.868 / 2020)$ & $\begin{array}{c}\text { Hunsrückisch e } \\
\text { talian }\end{array}$ \\
\hline & & $\begin{array}{l}\text { Rodeio (número não } \\
\text { identificado/2020) }\end{array}$ & Alemão \\
\hline & & $\begin{array}{l}\text { Pomerode (lei } n^{\circ} 2251 / 2010 \text { e lei } \\
\left.n^{\circ} 2907 / 2017\right)\end{array}$ & $\begin{array}{l}\text { Alemão e } \\
\text { pomerano }\end{array}$ \\
\hline
\end{tabular}

Fonte: elaboração própria

No quadro 2, percebemos que três estados patrimonializaram línguas de imigração e vinte e oito as cooficializaram.

A primeira língua de imigração a ser cooficializada no Brasil foi o pomerano, no município de Pancas (lei municipal n ${ }^{\circ}$ 987, de 27 de julho de 2007), no Espírito Santo. Hoje, seis cidades do estado do Espírito Santo têm o pomerano como língua cooficial, são elas: Laranja da Terra (lei $\mathrm{n}^{\circ} 510$, de 27 de junho de 2008), Santa Maria de Jetibá (lei no 1136, de 26 de junho de 2009), Vila Pavão (lei nº 671, de 11 de novembro de 2009), Domingos Martins (lei $\mathrm{n}^{\mathrm{o}}$ 2356, de 10 de outubro de 2011) e Itarana (lei no 1195 de 18 de março de 2016). No entanto, também percebemos a sua cooficialização nos municípios de Canguçu (lei no 3473, de 30 de julho de 2010) e de São Lourenço do Sul (número de lei não identificada), no estado do Rio Grande do Sul, e no município de Pomerode (lei no 2907/2017), em Santa Catarina. Ainda, dados do IPOL (2021) apontam que a cooficialização dessa língua está em processo de tramitação no município de Espigão do Oeste, em Rondônia. Outras cooficializações ocorrem com o talian, o Hunsrückisch, o Plattdeutsch e o alemão. A língua talian se encontra cooficializada nos municípios de Serafina Corrêa (lei no 2615, de 13 de novembro de 2009), 
de Flores da Cunha (lei municipal $\mathrm{n}^{\circ} 3.180$, de 27 de abril de 2015), de Nova Erechim (lei $\mathrm{n}^{\circ} 1.783$, de 11 de agosto de 2015), de Paraí (lei $\mathrm{n}^{\circ}$ 3122 , de 25 de agosto de 2015), de Nova Roma do Sul (lei $\mathrm{n}^{\circ} 1.310$, de 16 de outubro de 2015), de Bento Gonçalves (lei n ${ }^{\circ} 6.109$, de 07 de junho de 2016), de Fagundes Varela (lei $\mathrm{n}^{\circ}$ 1.922, de 10 de junho de 2016), de Antônio Prado (lei $\mathrm{n}^{\circ} 3.017$, de 28 de setembro de 2016), de Guabiju (lei $\mathrm{n}^{\circ} 1.315$, de 20 de abril de 2016), de Caxias do Sul (lei $\mathrm{n}^{\circ} 8.208$, de 09 de outubro de 2017), de Camargo (lei Ordinária $n^{\circ} 1.798$, de 31 de outubro de 2017), de Ivorá (lei municipal no 1.307, de 23 de março de 2018) e de Nova Pádua (lei $n^{\circ} 1.214$, de 26 de novembro de 2020), no estado do Rio Grande do Sul. Cabe salientar que esta mesma língua, juntamente com o Hunsrückisch, é cooficializada também no município de Ipumirim (lei $\mathrm{n}^{\mathrm{o}}$ 1.868/, de 17 de dezembro de 2020), no estado de Santa Catarina.

Por sua vez, além do município de Ipumirim, o Hunsrückisch é cooficializado em Antônio Carlos (lei $\mathrm{n}^{\circ}$ 132, de 01 de janeiro de 2010), no estado de Santa Catarina, e em Santa Maria do Herval (número de lei não identificado), no estado do Rio Grande do Sul. Quanto ao Plattdeutsch, esse se encontra cooficializado apenas no município de Westfália (lei $\mathrm{n}^{\circ}$ 1302/2016), no Rio Grande do Sul, enquanto a língua alemã se encontra cooficializada em Rodeio (número não identificado) e em Pomerode (lei no 2251, de 01 de setembro de 2010), no estado de Santa Catarina.

Ao observarmos os locais onde essas PLPN de línguas de imigrantes foram implementadas, percebemos que as ações de cooficialização estão centralizadas nos estados do Rio Grande do Sul, Espírito Santo e Santa Catarina, isto é, apenas três estados; os únicos onde também localizamos patrimonializações de línguas de imigrantes em nível estadual.

Cabe ressaltar que, ao realizarmos uma investigação mais detalhada das políticas de patrimonialização propostas pelos estados, sejam elas de línguas indígenas ou de imigrantes, percebemos que aquelas não citam nenhum tipo de medida que possibilite o seu acesso, proteção ou mesmo a 
implementação de políticas públicas educacionais. Isso posto, percebemos que as patrimonializações estaduais presentes no Brasil relegam a língua ao mero processo patrimonial, limitando-a ao campo social. Segundo Blanchet (2002), o fato de se tratar uma língua dessa forma não só a exclui da vida social como a marginaliza a uma esfera museológica em que não podemos utilizar o seu potencial. Nesse sentido, cabe nos questionarmos se, no Brasil, as cooficializações seguem os mesmos parâmetros das patrimonializações.

Nas cooficializações de âmbito municipal, notamos que a grande maioria estimula o aprendizado da língua citada ou prevê a obrigatoriedade da sua inclusão no sistema escolar por meio de PLPE. No entanto, com os dois quadros também percebemos que muitas vezes a patrimonialização de uma língua em âmbito estadual não condiz com a cooficialização encontrada em leis municipais, o que pode denotar falta de apoio ou de diálogo entre as entidades federativas.

Dessa forma, levando em conta o cenário administrativo do país, podemos encontrar paradoxos quando as PLPN não se relacionam nas esferas estadual e municipal. O mesmo pode se dar com o diálogo que deveria existir entre a legislação federal, estadual e municipal.

\section{A relação das PLPN com as PLPE nacionais}

O processo de desconcentração do poder da União permitiu que os estados e municípios passassem a gerir suas políticas linguísticas educacionais, de acordo com o contexto e a demanda de cada um, abrindo espaço para dar poder e voz às comunidades linguísticas. Esse processo é o oposto daquilo que vimos em relação às línguas regionais da França, posto que esse país ainda tem um forte poder centralizador.

No Brasil, as ações implementadas nesse contexto de autonomia administrativa são positivas para as populações locais, desde que haja 
uma real preocupação com a coerência e a complementaridade de ações conjuntas contextualizadas. Neste estudo, o papel do município na implementação de PLPN será abordado com maior deferência, já que essa foi uma das principais mudanças proporcionadas pela Carta Magna de 1988.

Assim, a figura abaixo ilustra a amplitude das ações politicolinguísticas municipais:

Figura 1 - Políticas linguísticas de cooficialização em âmbito municipal

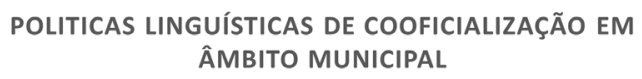

= Municipios sem lingua cooficializada m Municipios com lingua cooficializada

n Linguas estrangeiras cooficializadas $n$ Linguas indigenas cooficializadas

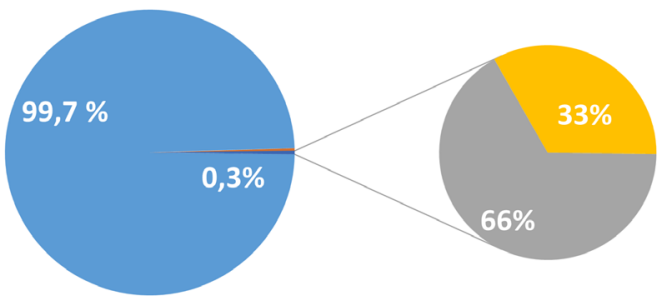

Fonte: elaboração própria.

Podemos observar que, na totalidade dos municípios brasileiros, $0,3 \%$ possui línguas cooficializadas, 33\% correspondem ao número de línguas indígenas e $66 \%$ ao de línguas de imigrantes. Muito embora o número de municípios que cooficializaram línguas de imigrantes corresponda ao dobro do número de línguas indígenas no Brasil, o único grupo linguístico a ser citado explicitamente e nominalmente na Constituição de 1988, em seu art. 210, tendo assegurada a utilização de sua língua materna no meio educacional, é a comunidade indígena. Sobre esse fato, Morello (2016, p. 4) assinala que: 
Representando um avanço em relação à Constituição de 1988, que havia reconhecido apenas aos indígenas o direito à sua língua e cultura, a lei de cooficialização cria uma nova jurisprudência e um novo mecanismo de reconhecimento para todas as línguas brasileiras, sejam indígenas, alóctones (isto é, trazidas de fora por processos de imigração), crioulas, de sinais ou afro-brasileiras. Em consequência, ela rapidamente ecoa em todo o território nacional, já que em centenas de municípios brasileiros há uma ou mais línguas faladas, além do português, pela maior parte de sua população. De 2002 a 2016, foram cooficializadas 11 línguas em 19 municípios brasileiros. Destas, quatro são alóctones, ou seja, faladas por descendentes de imigrantes: pomerano, em Santa Maria de Jetibá, Domingos Martins, Pancas, Laranja da Terra e Vila Pavão, no Espírito Santo, e em Canguçu, no Rio Grande do Sul; talian, em Serafina Corrêa, Paraí e Nova Roma do Sul, no Rio Grande do Sul, e em Nova Erechim, Santa Catarina; hunsrükisch, em Antônio Carlos, Santa Catarina, e Santa Maria do Herval, Rio Grande do Sul, e alemão, em Pomerode, Santa Catarina. Outras sete são autóctones, ou seja, indígenas: nheengatu, baniwa e tukano, em São Gabriel da Cachoeira, no Amazonas; guarani, em Tacuru, no Mato Grosso do Sul; akwê xerente, em Tocantínia, Tocantins; e macuxi e wapixana, em Roraima. No âmbito nacional, a Língua Brasileira de Sinais (Libras) passou também a ser cooficial em 2002, e a lei foi regulamentada em 2005. (MORELLO, 2016, p.4)

De fato, a Carta Magna de 1988 já preconizava a proteção e a segurança da pluralidade linguística antes mesmo do surgimento da DUDL. Dessa forma, foi a partir de 1988, no Brasil, que os temas ligados à extensão dos direitos sociais e políticos dos cidadãos e das chamadas minorias passaram a ter lugar na Lei Maior, resguardando os direitos aos costumes, culturas, línguas, organização social e crenças, como observado no artigo 215: 
Art. 215. O Estado garantirá a todos o pleno exercício dos direitos culturais e acesso às fontes da cultura nacional, e apoiará e incentivará a valorização e a difusão das manifestações culturais.

$\$ 1^{\circ} \mathrm{O}$ Estado protegerá as manifestações das culturas populares, indígenas e afro-brasileiras, e das de outros grupos participantes do processo civilizatório nacional (BRASIL, 1988).

Na citação acima, vemos a defesa da diversidade e da pluralidade cultural, o que engloba as línguas, tidas como um direito. Ainda que esse documento não mencione as comunidades de imigrantes presentes no território brasileiro ou suas especificidades, notamos a referência às manifestações das culturas populares, o que incluiria as línguas de imigrantes.

No tocante a outros documentos educacionais de âmbito nacional que precedem a Constituição de 1988 e se orientam pela LDB de 1996, ao fazermos um paralelo entre as referências ligadas às comunidades indígenas e às comunidades de imigrantes, percebemos que a primeira recebeu não só maior atenção como maior número de citações no decorrer do tempo.

A título de exemplo, em 1998, vemos pela primeira vez em um documento educacional de âmbito nacional, nos PCNs de língua estrangeira para o ensino fundamental, a menção ao termo "comunidades locais e imigrantes" como um dos critérios para escolha da inserção de uma língua estrangeira (LE) no currículo escolar. No entanto, apesar dessa preferência linguística possuir grande valor significativo e ser de caráter lógico, devido a ligações históricas e regionais, sua citação em documentos do setor federativo não levou à verdadeira inserção no meio educacional. Segundo Spinassé (2016), a

prática proposta nos PCNs só teria efeito se a estrutura do sistema escolar fosse diferente; no formato existente, as escolas das regiões de imigração, em sua maioria, também só oferecem o inglês como língua estrangeira, já que os alunos querem/devem inevita- 
velmente aprender o inglês e já que, como visto acima, oferecer outras línguas se torna tarefa complexa. (SPINASSÉ, 2016)

Assim, mesmo sendo prevista a possibilidade do aprendizado de LE diversas, a oferta de línguas ligadas às "comunidades locais e imigrantes", na prática, permaneceu reduzida. Esse fato se justifica por não ser apenas uma questão de permissão, mas das possibilidades do meio educativo e das ofertas do ambiente escolar.

Posteriormente, as OCEM (BRASIL, 2006) citam as comunidades de descendentes de imigrantes apenas nas proposições do capítulo de título Conhecimentos de Arte (item 4.3 - Inclusão, diversidade e multiculturalidade), ignorando suas particularidades linguísticas. Novamente, cabe salientar que, na prática do contexto escolar, as escolhas se concentraram "basicamente, em duas línguas, o inglês e o espanhol, pois estes são os idiomas mais comuns e de números mais expressivos e, no caso do espanhol, também a língua da grande maioria dos países que fazem fronteira com o Brasil." (SPINASSÉ, 2016).

No entanto, com relação aos PCN (2000) para o ensino médio, às DCN (2006) e ao PNE (2014), esses não chegam nem mesmo a assinalar a existência de tais comunidades. O seu reaparecimento recente ocorre apenas no texto da BNCC (2017) referente ao ensino fundamental, ligado ao componente de Língua Portuguesa. Nesse documento, observamos um discurso Político-Linguisticamente Correto (PLC), de acordo com a expressão proposta por Calvet (2016), em relação aos temas da diversidade linguística e cultural, do preconceito linguístico, das línguas ameaçadas de extinção e das políticas de cooficialização de línguas indígenas e de imigração.

Quanto ao texto da BNCC (2018) para o ensino médio, nele não encontramos a menção a peculiaridades linguísticas e/ou culturais relacionadas às línguas de imigrantes. Porém, esse documento ressalta a 
importância de as especificidades de povos indígenas serem consideradas na organização de currículos interculturais e bilíngues, bem como de propostas pedagógicas diferenciadas desenvolvidas pelas instituições escolares, em acordo com as Diretrizes Curriculares Nacionais.

Portanto, em relação às comunidades de línguas indígenas, a referência a esses povos aparece em todos os documentos posteriores a 1988, exceto nos PCN (2000) para o ensino médio. Todavia, notamos que muitos não consideram efetivamente suas especificidades linguísticas ou tecem diretrizes a favor dessas línguas. Os PCN (1998) para o ensino fundamental as representam como mero fator a ser considerado durante a escolha de uma LE (BRASIL, 1998, p. 23) e, no entanto, as OCEM (BRASIL, 2006) as colocam como uma das sugestões de conteúdos transversais a serem consideradas no ensino do espanhol, no âmbito "línguas e linguagens", e na parte relativa ao conhecimento artístico de arte, como um dos componentes ligados à inserção da arte no contexto escolar (BRASIL, 2006, p. 203).

Um documento que nos chama particular atenção são as DCN (2013). Sua foto central de capa mostra uma escola com três alunos indígenas, um prelúdio do índice com uma seção intitulada Diretrizes Curriculares Nacionais para a Educação Escolar Indígena. Dentre os objetivos propostos pelo documento, destacamos:

a) orientar as escolas indígenas de educação básica e os sistemas de ensino da União, dos Estados, do Distrito Federal e dos Municípios na elaboração, desenvolvimento e avaliação de seus projetos educativos;

b) orientar os processos de construção de instrumentos normativos dos sistemas de ensino visando tornar a Educação Escolar Indígena projeto orgânico, articulado e sequenciado de Educação Básica entre 
suas diferentes etapas e modalidades, sendo garantidas as especificidades dos processos educativos indígenas;

c) assegurar que os princípios da especificidade, do bilinguismo e multilinguismo, da organização comunitária e da interculturalidade fundamentem os projetos educativos das comunidades indígenas, valorizando suas línguas e conhecimentos tradicionais; d) assegurar que o modelo de organização e gestão das escolas indígenas leve em consideração as práticas socioculturais e econômicas das respectivas comunidades, bem como suas formas de produção de conhecimento, processos próprios de ensino e de aprendizagem e projetos societários;

e) fortalecer o regime de colaboração entre os sistemas de ensino da União, dos Estados, do Distrito Federal e dos Municípios, fornecendo diretrizes para a organização da Educação Escolar Indígena na Educação Básica, no âmbito dos territórios etnoeducacionais;

f) normatizar dispositivos constantes na Convenção 169, da Organização Internacional do Trabalho, ratificada no Brasil, por meio do Decreto Legislativo $n^{\circ} 143 / 2003$, no que se refere à educação e meios de comunicação, bem como os mecanismos de consulta livre, prévia e informada;

g) orientar os sistemas de ensino da União, dos Estados, do Distrito Federal e dos Municípios a incluir, tanto nos processos de formação de professores indígenas, quanto no funcionamento regular da Educação Escolar Indígena, a colaboração e atuação de especialistas em saberes tradicionais, como os 
tocadores de instrumentos musicais, contadores de narrativas míticas, pajés e xamãs, rezadores, raizeiros, parteiras, organizadores de rituais, conselheiros e outras funções próprias e necessárias ao bem viver dos povos indígenas;

h) zelar para que o direito à educação escolar diferenciada seja garantido às comunidades indígenas com qualidade social e pertinência pedagógica, cultural, linguística, ambiental e territorial, respeitando as lógicas, saberes e perspectivas dos próprios povos indígenas (BRASIL, 2006, p. 386).

Dessa forma, acreditamos que as DCNs são um dos poucos documentos que nortearam a educação nacional, onde encontramos reflexões e orientações acerca das práticas linguísticas em escolas indígenas. Nele, vemos a preocupação com o desenvolvimento de uma educação diferenciada para os níveis infantil, fundamental e médio, envolvendo especificidades ligadas à Educação Especial, à Educação de Jovens e Adultos e à Educação Profissional e Tecnológica, assim como a discussão sobre o projeto político-pedagógico das escolas indígenas, o Currículo da Educação Escolar Indígena e a Avaliação e a formação e profissionalização de professores indígenas.

No ano de 2020 foram aprovadas as Diretrizes Curriculares Nacionais para a oferta de Educação Plurilíngue. ${ }^{11}$ Essa PLPE cita o panorama linguístico e os contextos bilíngues de educação existentes no país. No entanto, é interessante notarmos que, nas especificações relativas à parte histórica, encontramos apenas subtemas como: Educação Indígena, Educação de Surdos e Educação em regiões de fronteiras.

11 https://www.in.gov.br/en/web/dou/-/sumula-de-pareceres-278232310

http://portal.mec.gov.br/index.php?option=com docman\&view=download\&alias=156861-pceb002-

20\&category_slug=setembro-2020-pdf\&Itemid=30192 
No subtema Educação Indígena, percebemos a citação de políticas de cooficialização municipais de línguas indígenas e de imigração. $O$ fato desse subtema não abranger o termo "imigração" em seu título, ou do termo não ser alvo de um subtema único, aponta para o lugar secundário que as línguas de imigração têm ocupado em documentos federais.

Essas novas DCN (2020) também evidencia o impacto do processo de desconcentração administrativa no país, pois, ao citar PLPN, mostra a influência de políticas linguísticas educacionais locais em legislações nacionais. No entanto, ao mesmo tempo em que há um aparente respeito à autonomia dos entes federativos prevista na Carta Magna, as DCN (2020) enfatizam imposições encontradas na BNCC (2018) ao destacar que a língua inglesa é a única LE obrigatória na área de Linguagens, além de sugestionar o ensino da língua espanhola no ambiente escolar.

Nesse ponto, consideramos um retrocesso privilegiar apenas a língua inglesa como LE no âmbito das linguagens em detrimento do discurso presente no documento, que ressalta a importância da diversidade linguística e cultural. Destacamos que as dificuldades regionais ligadas à falta de concursos, à disponibilidade de professores de diferentes áreas e à falta de investimento na educação podem se tornar fatores determinantes na escolha das LE ofertadas. Assim, a obrigatoriedade da língua inglesa limita as possibilidades locais e faz com que se privilegiem as leis, em vez de propiciar um sentimento motivador de pertencimento e inclusão, enfatizando-se as especificidades das comunidades linguísticas.

\section{Conclusão}

A finalidade deste artigo foi tecer uma investigação documental com vistas a compreender o processo de reconhecimento da diversidade linguística do país, por meio de cooficializações municipais e patrimonializações estaduais de línguas minoritárias de dois grupos, 
indígenas e de imigração.

Esse processo tornou-se possível graças ao processo de desconcentração das PP, encontrado a partir de 1988, ano de promulgação da Constituição em vigor.

Assim, iniciamos este estudo dissertando acerca da interseção teórica entre os conceitos de política pública e de política linguística. A fim de contemplar o cruzamento entre ambas as áreas de estudo, refletimos sobre o conceito de Política Linguística Pública (PLP) e suas diferentes formas, como: as PLPE, as PLPR e as PLPN, analisadas neste trabalho.

Ao buscarmos entender a redefinição do papel da União, estados e, mormente, municípios em relação à elaboração política, percebemos que as PLPN deveriam possuir uma estreita relação com o reconhecimento da autonomia regional e com o processo de desconcentração do poder público previsto pela Constituição de 1988. Essa atitude seria uma demonstração de confiança por parte do governo federal para com os governantes municipais e estaduais, permitindo que esses tenham, de fato, o poder de legislar sobre as línguas, a cultura e a educação local. Desse modo, bastaria que um consenso se estabelecesse no quadro do município ou do estado em questão para a elaboração de uma PLP coerente e contextualizada com o território onde ela fosse implementada. No entanto, hodiernamente, percebemos a constante falta de diálogo entre diferentes entes federados, fazendo com que surjam políticas paradoxais e em desacordo com os contextos diferenciados do Brasil.

Os resultados mostram ainda a necessidade de um real planejamento democrático que atenda essas línguas minorizadas, não de políticas linguísticas que apenas aparentem respeitar a desconcentração política prevista na Constituição de 1988 ou o multilinguismo brasileiro e suas diferenças. Para que isso ocorra, a inserção de uma LE no sistema educacional deveria se fazer não em caráter obrigatório, mas considerar as singularidades e as especificidades das comunidades linguísticas. 
Conforme destacado neste artigo, algumas regiões do Brasil possuem grande potencial bilíngue a ser explorado, chegando a ter línguas de herança cooficializadas em estados e municípios. Logo, a diversidade linguística e a pluralidade cultural do Brasil, que conta com mais de 50 línguas de imigração, poderiam e deveriam ser consideradas como fatores capazes de contribuir para um ensino de LE mais eficaz.

Salientamos que conflitos entre níveis são comuns no meio educacional, pois, conforme observado durante a análise, governos podem planificar políticas consideradas inadequadas para certas regiões e/ou localidades. No entanto, considerando os impactos e contradições presentes no contexto político-linguístico encontrado hoje no Brasil, acreditamos que o real respeito à autonomia dos entes federados dada pela Lei Maior de 1988 bem como um verdadeiro planejamento democrático são condições primordiais para a elaboração de mudanças que atendam aos interesses diversos da sociedade brasileira.

\section{Referências}

BALL, Stephen J. Educational reform: a critical and post-structural approach. Buckingham: Open University Press, 1994.

BALL, Stephen J.; BOWE, Richard. Subject departments and the implementation' of National Curriculum policy: an overview of the issues. Journal of Curriculum Studies, p. 97-115, jul 2006

BOWE, Richard.; BALL, Stephen.; GOLD, Anne. Reforming education \& changing schools: case studies in policy sociology. London: Routledge, 1992.

BLANCHET, Philippe. La politisation des langues régionales en France. Langues et territoires. Revue Hérodote, Paris, v. 105, n. 2, p. 85-101, 2002. Disponível em : https://www.cairn.info/revue-herodote-2002-2-page-85. 
htm. Acesso em: 12 abr. 2021.

BNCC - Base Nacional Comum Curricular. A Base. MEC: 2017. Disponível em: http://basenacionalcomum.mec.gov.br/a-base . Acesso em: 23 set. 2020.

BNCC - Base Nacional Comum Curricular. A Base. MEC: 2018. Disponível em: http://basenacionalcomum.mec.gov.br/a-base . Acesso em: 23 set. 2020.

BOYER, Henri. Langue et identité: Sur le nationalisme linguistique. Lamber-Lucas, Limoges. France. Janvier: 2009.

BRASIL. Constituição da República Federativa do Brasil de 1988. 05 out.1988. Presidência da República. Brasília: DF, 1988. Disponível em: http://www.planalto.gov.br/ccivil_03/constituicao/constituicao.html Acesso em: 24 set. 2020.

BRASIL. Diretrizes Curriculares Nacionais da Educação Básica (DCN). Ministério da Educação. Secretaria de Educação Básica. Diretoria de Currículos e Educação Integral. Brasília: MEC, SEB, DICEI, 2013. Disponível em: http://portal.mec.gov.br/index.php?option=com_docman\&view=download\&alias=13448-diretrizes-curiculares-nacionais-2013-pdf\&Itemid=30192 . Acesso em: 24 set. 2020.

BRASIL. Lei no 9.394, de 20 de dezembro de 1996. Estabelece as diretrizes e bases da educação nacional. Brasília, DF, 1996. Disponível em: http://www. planalto.gov.br/ccivil_03/leis/19394.htm. Acesso em: 6 jun. 2021

BRASIL. Lei $n^{\circ}$ 13.005, de 25 de junho de 2014. Aprova o Plano Nacional de Educação - PNE e dá outras providências. Brasília, DF, 2014. Disponível em: http://www.planalto.gov.br/ccivil_03/_ato2011-2014/2014/lei/113005. 
htm. Acesso em: 6 jun. 2021

BRASIL. Orientações Curriculares para o Ensino Médio: linguagens, códigos e suas tecnologias. Ministério da Educação. Secretaria de Educação Básica. Brasília: SEB/MEC, 2006. Disponível em: http://www.letras.ufmg.br/ profs/reinildes/dados/arquivos/ocem.pdf. Acesso em: 24 set. 2020.

BRASIL. Parâmetros curriculares nacionais: ensino fundamental (PCN). Ministério da Educação, Secretaria da Educação Média tecnológica. Brasília, DF, 1998. Disponível em: http://portal.mec.gov.br/seb/arquivos/pdf/ livro01.pdf. Acesso em: 24 set. 2020

BRASIL. Parâmetros curriculares nacionais: ensino médio (PCN). Ministério da Educação, Secretaria da Educação Média tecnológica. Brasília, DF, 2000. Disponível em : http://portal.mec.gov.br/setec/arquivos/pdf/ BasesLegais.pdf. Acesso em: 24 set. 2020.

CALVET, Louis-Jean. La Méditerranée: Mer de nos langues. Paris: CNRS éditions, 2016.

CALVET, Louis-Jean. Le marché aux langues: Les effets linguistiques de la mondialisation. Paris: Plon, 2002a.

CALVET, Louis-Jean. Les politiques linguistiques. Paris: PUF, 1996.

CALVET, Louis-Jean. Sociolinguística: uma introdução crítica. Tradução de Marcos Marcionilo. São Paulo: Parábola, 2002b.

CDI - Comisión Nacional para el Desarollo de los Pueblos Indígenas. Sítio eletrônico CDI. CDI: 2017. Disponível em: https://www.gob.mx/cdi . Acesso em: 25 set. 2020.

DUDC - Declaração Universal sobre a Diversidade Cultural. Declara- 
ção Universal sobre a Diversidade Cultural. Unesco: 2002. Disponível em: http://unesdoc.unesco.org/images/0012/001271/127160por.pdf . Acesso em: 27 set. 2020.

DUDL - Declaração Universal dos Direitos Linguísticos. Declaração Universal dos Direitos Linguísticos, de 1996. 1996. Disponível em: http://www. dhnet.org.br/direitos/deconu/a_pdf/dec_universal_direitos_linguisticos. pdf . Acesso em: 27 set. 2020.

DYE, Thomas D. Understanding Public Policy. Englewood Cliffs, N.J.: PrenticeHall, 1984.

FOUCAULT, Michel. Microfísica do Poder. Tradução de Roberto Machado.11 a ed., Rio de Janeiro: Graal, 1997.

FUNAI - Fundação Nacional dos Índios. Sítio eletrônico FUNAI. FUNAI: 2017. Disponível em: http://www.funai.gov.br/. Acesso em: 21 set. 2020. Acesso em: 27 set. 2020

IPOL - Instituto de Investigação e Desenvolvimento em Política Linguística. Lista de línguas cooficiais em municípios brasileiros. Disponível em: http://ipol.org.br/lista-de-linguas-cooficiais-em-municipios-brasileiros/?fbclid=IwAR0IruU-wtnLU_ptYxsc9ab-htv_VEUjVXysYGoxFZca4a4PxxkJVGuvQTg. Acesso em: 28 mar. 2021.

LASWELL, Harold Dwight. Politics: Who, Gets What, When, How. Cleveland: Meridian Books, 1936.

LECLERC, Jacques. L’aménagement linguistique dans le monde. Québec: Universidade Laval, 2012. Disponível em: www.tlfq.ulaval.ca/axl . Acesso em: 28 set. 2020 .

Lowi, Theodore J. American Business, Public Policy, Case-Studies, and Po- 
litical Theory. World Politics, v. 16, n. 4, p. 677-715, 1964, pp. 677-715. Disponível em: https://www.jstor.org/stable/2009452?seq=1\#metadata_info_ tab_contents. Acesso em: 12 abr. 2021.

MORAES, Alexandre de. Direito Constitucional. 19ª edição. São Paulo: Editora Atlas, 2006.

MORELLO, Rosângela. Leis e línguas no Brasil: o processo de cooficialização e suas potencialidades. IPOL: Instituto de Investigação e Desenvolvimento em Política Linguística, 2015a.

MORELLO, Rosângela. A Política de Cooficialização de Línguas no Brasil. Platô - Revista do Instituto Internacional da Língua Portuguesa. v. 1, p. 8-17, 2016. Disponível em: Disponível em: http://www.youblisher.com/p/ 783318-Plato-Volume-1-N-1-Coloquio-de-Maputo-V1-2/. Acesso em: 12 abr. 2021.

MORELLO, Rosângela. Talian: protagonismo na luta pelo reconhecimento cultural e fortalecimento pela lei de cooficialização. 25 out. 2015. IPOL, 2015b. Disponível em: http://e-ipol.org/talian-protagonismo-na-luta-pelo-reconhecimento-cultural-e-fortalecimento-pela-lei-de-cooficializacao/. Acesso em 27 set. 2020.

MOSELEY, Christopher. Atlas of the World's Languages in Danger. 3rd edn. Paris, UNESCO, 2010. Publishing. Online version. Disponível em: http:// www.unesco.org/culture/en/endangeredlanguages/atlas. Acesso em: 27 set. 2020 .

OLIVEIRA, Gilvan Müller de. Política Lingüística na e para além da Educação Formal. Estudos Lingüísticos XXXIV, p. 87-94, 2005. Disponível em: http://etnolinguistica.wdfiles.com/local--files/journal\%3Aestudos/oliveira_2005_politica.pdf. Acesso em: 27 set. 2020. 
PETERS, B. Guy. American Public Policy. Chatham, N.J.: Chatham House. 1986.

PIB. Na atualidade. PIB: [201-d]. Disponível em: https://pib.socioambiental.org/pt/c/politicas-indigenistas/o-que-e-politica-indigenista/na-atualidade. Acesso em: 28 set. 2020.

ROCHA, Roberto. A gestão descentralizada e participativa das políticas públicas no Brasil. Revista Pós Ciências Sociais. v. 1 n. 11. São Luis/MA: 2009. Disponível em: http://www.ppgcsoc.ufma.br/index.php?option=com_content\&view $=$ article\&id=318\&Itemid=114. Acesso em: 28 set. 2020.

ROUSSEAU, Louis-Jean. Élaboration et mise en oeuvre des politiques linguistiques. Cahiers du Rifal. Office québécois de la langue française. Québec. 2015. Disponível em: https://hal.archives-ouvertes.fr/hal-02424020/ document. Acesso em: 28 set. 2020.

SANTA CATARINA. Lei no 14.951/2009 de 11 de novembro de 2009. Declara integrante do patrimônio histórico e cultural do estado o dialeto "talian”, originado dos italianos e descendentes radicados em Santa Catarina. Diário Oficial do Estado de Santa Catarina. Assembleia Legislativa do Estado de Santa Catarina no 18.728, Florianópolis, SC, 11 nov. 2009. Disponível em: https://leisestaduais.com.br/sc/lei-ordinaria-n-14951-2009-santa-catarina-consolida-as-leis-que-dispoem-sobre-o-patrimonio-cultural-do-estado-de-santa-catarina. Acesso em: 12 abr. 2020.

SANTA CATARINA. Lei no 17.565/2018 de 06 de agosto de 2018. Consolida as Leis que dispõem sobre o Patrimônio Cultural do Estado de Santa Catarina. Diário Oficial do Estado de Santa Catarina no 20.829. Assembleia Legislativa do Estado de Santa Catarina, Florianópolis, SC, p. 48, 08 ago. 2018. Disponível em: https://doe.sea.sc.gov.br/index.php/buscar-jornal- 
-antigo/. Acesso em: 12 abr. 2021.

SÉRIOT, Patrick. Les langues ne sont pas des choses: Discours sur la langue et souffrance identitaire en Europe centrale et orientale. Paris: Editions Pétra, 2010.

SOUZA, Marina Mello de Menezes Felix de. As Políticas Linguísticas Públicas Educativas no Brasil e o processo de desconcentração política pós1988. In: SAVEDRA, Mônica; PEREIRA Telma Cristina; GAIO, Mario Luis. (org.). Repertórios Plurilíngues em Situação de Contato. 1ed. Rio de Janeiro: Editora - LCV, v. 1, p. 74-88, 2019. Disponível em: http://labpec-uff.com.br/documentos/SAVEDRA-PEREIRA-GAIO\%20\%20Repertorios\%20Plurilingues\%20em\%20situacao\%20de\%20contato.pdf . Acesso em: 28 set. 2020.

A desconcentração política e o seu impacto nas políticas linguísticas públicas educacionais (PLPE) no Brasil. 270 f. Tese (Doutorado em Estudos da Linguagem) - Instituto de Letras. Universidade Federal Fluminense, Niterói, Rio de Janeiro. Disponível em: https://app.uff.br/riuff/bitstream/1/7190/1/Tese\%20-\%20SOUZA\%2C\%20Marina.pdf. Acesso em: 29 mar. 2021

; PEREIRA, Cristina de Almeida Silva Pereira. Politique Linguistique et Politique Publique: Une Proposition d' Intersection Théorique. Cahiers International Sociolinguistique, v. 15, p. 167, 2019. Disponível em: https://www.cairn.info/revue-cahiers-internationaux-de-sociolinguistique-2019-1-page-167.htm. Acesso em: 28 set. 2020.

SPINASSÉ, Karen Pupp. Fazendo política linguística em sala de aula: ações didático-pedagógicas pela manutenção da língua minoritária Hunsrückisch. ReVEL, v. 14, n. 26, 2016. Disponível em: < http://www.revel.inf.br/ files/b1bc51340629442bb1f83ec68b22fcf0.pdf > . Acesso em: 28 set. 2020. 
UNESCO - Organização das Nações Unidas para a Educação, a Ciência e a Cultura. Relatório Mundial da Unesco. Investir na diversidade cultural e no diálogo. UNESCO: 2009. Disponível em: http://unesdoc.unesco.org/ images/0018/001847/184755por.pdf . Acesso em: 23 set. 2017

Multilingualism and linguistic rights: cooficialization and patrimonialization as forms of recognition of minority languages

Abstract: The process of administrative deconcentration that has been in place since the 1988 Constitution has triggered language policies of co-officialization and patrimonialization of minority languages, generating glotopolitical actions in multilingual contexts, especially in relation to indigenous languages and languages of immigrants. In this article, based on a bibliographic and documentary approach, we analyze some municipal, state, and federal educational legislative documents in order to understand the action of different glopolitical actors. Our analysis is based on the concepts of Linguistic Policies, Public Policies, and Linguistic Rights. Contextualizing our reflection in the process of redefining the role of the Union and the federative entities, we perceive the policies of co-officialization and patrimonialization of minority languages as an indication of regional autonomy. However, the results also show the need for real democratic planning to attend these minority languages. Keywords: Language policies. Public policies. Language rights. 1988 Brazilian Constitution. Minority languages.

Recebido em: 05/03/2021

Aceito em: 07/06/2021 